Economic Computation and Economic Cybernetics Studies and Research, Issue 1/2019; Vol. 53

\author{
Zheng-Zheng Li, PhD Student \\ Department of Finance, Ocean University of China \\ De-Ping Xiong, PhD (Corresponding author) \\ School of Finance, Yunnan University of Finance and Economics \\ E-mail:xiongdeping@126.com \\ Lavinia Daniela MIHIT, PhD Student West University of Timisoara \\ Doctoral School of Economics and Business Administration \\ Cristina STANCIU - MANDRULEANU, PhD Student \\ The Bucharest University of Economic Studies \\ Economist Florin COSTEA, Head of Finance Hella Romania
}

\title{
HOW DOES ECONOMIC POLICY UNCERTAINTY EFFECT SIGNALING EXCHANGE RATE IN JAPAN?
}

Abstract. In this paper, we apply the bootstrap rolling window sub-sample test to examine the causal links of the exchange rate (ER) and the economic policy uncertainty (EPU) in Japan. This method provides more accurate evidence of a relationship between these two variables considering the structural changes. The empirical results show that a positive or negative relationship between the EPU and the ER exist. This finding is basically consistent with the Expected Value Model in most periods. Specifically, when the Yen is depreciating, the EPU increases accordingly and vice versa. In addition, the Yen appreciates when the EPU is increasing in crisis periods, which results from the Yen's risk-off attribute. The findings illustrate that the Yen is an advantageous investing choice as a hedge against depreciation in the crisis stage. Japanese authorities could intervene with the ER to influence the public's expectation or the EPU to smoothly stabilize the economy.

Keywords: Economic policy uncertainty; Exchange rate; Japanese Yen; Bootstrap rolling window; Risk-off characteristic.

JEL Classification: C32, E52, F31

\section{Introduction}

This paper tests whether a causal relationship exists between the economic policy uncertainty (EPU) and the exchange rate (ER) in Japan. After the collapse of the Bretton Woods Regime in 1975, the Japanese authority declared that they would adopt a floating ER system for the Yen. The recession in the 1980s, which was caused by the Plaza Accord, strengthened the Yen; this phenomenon created an

DOI: $10.24818 / 18423264 / 53.1 .19 .09$ 
Zheng-Zheng Li, De-Ping Xiong, Lavinia Daniela Mihit, Cristina Stanciu - Mandruleanu, Florin Costea

incentive for expansionary monetary policies. However, the Plaza Accord agreement is significant in that it reflects Japan's emergence as a real participant in managing the international monetary system. As the Japanese economy recovered, the Yen became a strong global currency because of its stable performance. At the beginning of the 1990s, in Japan the real estate and stock market bubble burst and the foreign exchange market went into a tailspin. Since then, Japan has suffered from sluggish economic growth. More serious, the global financial crisis in September 2008 threatened the entire world economy (Ganea, 2015;Badîrceaet al., 2016). Combining the global economic recession and the appreciation in the Yen led to a severe decrease in exports. In March 2011, a catastrophic earthquake and tsunami struck northeastern Japan. Thus, the government budget deficit grew to a peak, and the deficit-to-GDP ratio increased to approximately 200\%. The Japanese economy required a stimulus to escape this pattern of slow growth in the long-term. Abe proposed a series of economic policies, including monetary expansion, fiscal stimulus, and structural reforms, called "three arrows" in 2013. The ER of the Yen experienced huge fluctuations during these periods. The foreign exchange market received a steady flow of information types, including changes in economic policies, economic fundamentals, social and political conditions, and financial market sentiment; this led to the ER becoming sensitive to economic variables. Thus, the conclusion is that a certain relationship between the ER and other economic variables exists.

We study this topic in Japan for several reasons. First, Japan has experienced significant fluctuations in the ER since post-1980. The Yen experienced a trough in 1985 of 250 Yen per Dollar and peaked with the Plaza Agreement in 1995 at approximately 85; this was an appreciation of nearly $300 \%$. The government intervention on the Yen's behalf trapped Japan in the "Lost Decades". Furthermore, Japan was in a depreciation period until 1998. The upward surged in domestic financial instability in 1997 and, undoubtedly, the crisis in the Asian emerging markets contributed to the Yen's rapid depreciation by August 1998. Thirdly, the Yen's next real appreciation cycle began between 2008 and 2012, in which it served a safe-haven role in the crisis periods. Abe implemented an ER invention to stimulate the economy and extract Japan from an economic recession; this terminated this cycle of appreciation. Finally, the Yen depreciated until 2016; this was ended by the 'Britain exiting from the Europe Union' event. Thus, the risk-off characteristic was presented again in the currency market. 
How Does Economic Policy Uncertainty Effect Signaling Exchange Rate In Japan?

In recent decades, the negative effects that the EPU has on economic activities have been widely recognized. Bloom et al. (2007) believe that higher uncertainty causes firms to temporarily pause their investment and hiring and further generate short, sharp recessions. Recently, Brogaard and Detzel (2015) provide evidence that the EPU of the USA slows equity mainly by increasing the risk premium. However, Ulrich (2012) shows positive volatility spillovers between the EPU and equity returns. The ER is vital to foreign trade and international capital investments for a country, in particular for Japan's export-dependent economy. The ER is an important part of the transmission mechanism in the determination of economic policy because movements in the ER have a significant effect on the macroeconomy. Thus, exploring the linkage between the EPU and economic variables becomes a crucial issue.

Frankeland and Meese (1987) note the role of uncertainty in separately explaining the ER determination based on the partial and general equilibrium setting. They analyze the impact of domestic uncertainties (including the conditional volatilities of the monetary policy, the inflation-target and the productivity shocks) on the dollar-based real ERs of the G6 countries. However, monetary policy uncertainty is not equal to the conception of the EPU. According to Baker et al. (2016), the EPU index is composed of uncertainties regarding tax spending and monetary and regulatory policy by the government. The EPU index is calculated from the following three components: the frequency that economic policies appear in the newspaper, the number of expired codes, and the extent of forecaster disagreements over future inflation and government purchases. Sin (2015) investigates the effect of the EPU of China and their impacts on the real ERs of Taiwan and Hong Kong in both the short run and the long run. Using the nonparametric causality-in-quantiles test, Balcilaret al. (2016) note that the EPU does not affect ER returns regardless of whether the returns are high or low in Japan.

Previous researchers have conducted few investigations regarding the EPU and the ER in a specific country. Researchers also ignore the structural changes in their methods. The role of the EPU has not been empirically concluded in relevant studies. Beckmann and Czudaj (2017) rely on a Vector Auto Regression (VAR) framework to analyze the path of the ER expectation responses to shocks on the EPU. In addition, their analysis has been restricted to policy uncertainty in the USA, also leaving the analysis of several alternatives (potentially country-specific) as an unaddressed issue. However, this literature, in general, only considers the 
Zheng-Zheng Li, De-Ping Xiong, Lavinia Daniela Mihit, Cristina Stanciu - Mandruleanu, Florin Costea

full-sample causality relationship and is susceptible to misleading results. The conclusions in the presence of parameter instability because of structural changes are less persuasive. In recent decades, Japan has experienced economic restructuring and structural changes in its financial policy; these include external crises and internal interventions. The two financial crises, the Asian crisis in 1997 and the global financial crisis in 2008, exerted huge shocks to the global economy. The official intervention included the Zero Lower Bound announced in 1999, the three Quantitative Easing (QE) programs in 2001, 2010, and 2013, and the policy towards the ageing problem and the gloomy economy under Abe. Considering the presence of structural changes, the dynamic links between the two series will show instability across different sub-samples, and empirical studies examining the full-sample relationship may suffer from inaccurate results.

This paper presents an important contribution to the literature by considering the time variation in the causal links between the EPU and the ER. The bootstrap rolling-window method is distinctive from most conventional mathematical approaches, which cannot identify the full-sample, especially the sub-sample relationships between the time series, and cannot reveal how such relationships vary over time. This issue can be solved by allowing the causal relationship between the two series to be time-varying rather than using full-sample data that assume the single causality holds in every time period. In this paper, we test for causality on the rolling sub-sample with a fixed-size window, thus allowing us to consider structural changes in the sample and the evolution of the causality between sub-periods rather than simply testing for causality on the full-sample, which assumes a permanent causal relationship. The empirical result shows that, in several sub-samples, the EPU has different (positive or negative) effects on the ER in Japan, while the EPU will change in response to the appreciation or depreciation of the ER in other periods. The results are basically consistent with the Expected value theory (Engel and West, 2005) in that the Yen depreciates when the EPU increases in the most recent period, and the hedging function contributes to the deviation of these two variables.

This paper is structured as follows. Section 2 introduces the Expected Value Model. Section 3 explains the methodology of the bootstrap rolling-window causality test. Section 4 describes the data and empirical results and the policy implications. Section 5 concludes the study. 
How Does Economic Policy Uncertainty Effect Signaling Exchange Rate In Japan?

\section{Expected Value Model}

The Expected Value Model proposed by Engel and West (2005) provides a theoretical basis for analyzing the impact of the EPU on the ER. In this model, the ER represents a discounted value of the expectations of future fundamentals. The current ER can be expressed as follows:

$E\left(E R_{t}\right)=(1-b) \sum_{j=0}^{\infty} b^{j} E_{t}\left(f_{1, t+j}\right)+b \sum_{j=0}^{\infty} b^{j} E_{t}\left(f_{2, t+j}\right)$

where denotes a discount factor with, represents the expected ER. The systematic components and, include money supply, interest rates and other endogenous observable fundamentals. Similarly, EPU can be explained as

$$
E P U_{t}=(1-b) \sum_{j=0}^{\infty} b^{j} E_{t}\left(u_{1, t+j}\right)+b \sum_{j=0}^{\infty} b^{j} E_{t}\left(u_{2, t+j}\right)
$$

where unsystematic components and denote unobservable fundamentals, which may be revisions in expectations or risk premia (Engel and West, 2005); is the exchange rate of the home currency price of foreign currency, which consists of a systematic and an unsystematic component. As the following function presents:

$E R_{t}=(1-b) \sum_{j=0}^{\infty} b^{j} E_{t}\left(f_{1, t+j}+u_{1, t+j}\right)+b \sum_{j=0}^{\infty} b^{j} E_{t}\left(f_{2, t+j}+u_{2, t+j}\right)$

That is,

$$
E R_{t}=E\left(E R_{t}\right)+E P U_{t}
$$

We argue that the EPU matters for both the systematic and the unsystematic components. Specifically, the expected policy shocks influence the path of expected fundamentals. Furthermore, the EPU should be an adequate approximation of the unsystematic component as it can influence the actual or expected fluctuation or the risk premia. Overall, we distinguish between the expected and unexpected effects on the ER stemming from the policy uncertainty by considering both the expectations and the forecast error.

\section{Methodology}

\subsection{Bootstrap full-sample causality test and Parameter stability test}

Sims et al. (1990) propose that the Likelihood Ratio (LR) may not have standard asymptotic distributions because structural changes exist in the VAR model. In this scenario, Shukur and Mantolos (2000) prove the residual-based bootstrap method (RB method) is particularly excellent for standard asymptotic tests and for power and size properties in small sample corrected LR tests.

The RB-based modified-LR statistic in VAR process can be written as: 
Zheng-Zheng Li, De-Ping Xiong, Lavinia Daniela Mihit, Cristina Stanciu - Mandruleanu, Florin Costea

$$
y_{t}=\Phi_{0}+\Phi_{1} y_{t-1}+\ldots+\Phi_{p} y_{t-p}+\varepsilon_{t}, t=1,2, \ldots, T
$$

where $y_{t}=\left(y_{E P U, t}, y_{E R, t}\right)^{\prime}$ subjects to i.i.d. process with nonsingular covariance matrix, and optimal lag-length $p$ is selected based on the Schwarz Information Criteria (SIC). In particular, we can also get the equation as follows:

$\left[\begin{array}{c}y_{E P U, t} \\ y_{E R, t}\end{array}\right]=\left[\begin{array}{c}\varphi_{10} \\ \varphi_{20}\end{array}\right]+\left[\begin{array}{cc}\varphi_{E P U, E P U}(L) & \varphi_{E P U, E R}(L) \\ \varphi_{E R, E P U}(L) & \varphi_{E R, E R}(L)\end{array}\right]\left[\begin{array}{c}y_{E P U, t} \\ y_{E R, t}\end{array}\right]+\left[\begin{array}{c}\varepsilon_{E P U, t} \\ \varepsilon_{E R, t}\end{array}\right]$

where $y_{E P U, t}$ is the EPU, and $y_{E R, t}$ is the ER. $\varphi_{i j}(L)=\sum_{k=1}^{p+1} \varphi_{i j, k} L^{k}, L$ is the lag operator $\left(L^{k} x_{t}=x_{t-k}\right)$. In addition, $\varphi_{12, k}=0, k=1,2,3, \cdots, s$. Implies ER does not Granger cause the EPU. The null hypothesis that the EPU does not Granger cause the ER can be similarly tested.

In addition, Sup- $F$, Mean- $F$ and Exp- $F$ tests can be used to investigate short-run parameter stability(Andrews and Ploberger, 1994). We examine the long-run stability parameter by the $L c$ test from Nyblom (1989) and Hansen (1992)by calculating from the sequence of LR statistics.

\subsection{Sub-sample rolling-window estimation}

Supposing there are $\mathrm{m}$ observations in the rolling window, then we can obtain T-s sub-samples, that is, $\tau$-s $+1, \tau$-s, $\ldots, \mathrm{T}$ for $\tau=\mathrm{s}, \mathrm{s}+1, \ldots, \mathrm{T}$. The RB-based modified-LR test can estimate every sub-sample and ensure the accuracy of the results. We can conclude if there exists causality between ER and EPU according to the bootstrap $p$-values. Furthermore, their average $\left(N_{b}^{-1} \sum_{21, k}^{p} \hat{\varphi}_{21, k}^{*}, N_{b}^{-1} \sum_{12, k}^{p} \hat{\varphi}_{12, k}^{*}\right)$ indicates the impact of the EPU and the ER, which are the explained variables, respectively. In addition, $N_{b}^{-1}$ is the repetitions using the bootstrap, and both $\hat{\varphi}_{21, k}^{*}$ and $\hat{\varphi}_{12, k}^{*}$ are bootstrap estimates. In the confidence interval of $95 \%$, the lower and upper limits are the 2.5th and 97.5th quantiles of each of the $\hat{\varphi}_{21, k}^{*}$ and $\hat{\varphi}_{12, k}^{*}$.

In the rolling-window estimation, the window size is an important issue to be considered. A large size of window can promote the accuracy, but it reduces the 
How Does Economic Policy Uncertainty Effect Signaling Exchange Rate In Japan?

representativeness owing to the existence of heterogeneity. On the contrary, a small window size may improve the representativeness and reduce accuracy. Thereby, we should choose a proper window size to ensure both the accuracy as well as the representativeness. Pesaran and Timmerman (2005) prove that the optimal choice of window size depends on the persistence and size of the break considering the structural change, which is according to the square root mean square error. More precisely, based on Monte Carlo simulations, they argue that the bias in autoregressive (AR) parameters is minimized with a window size of as low as 20 when there are frequent breaks.

\section{Data and Empirical Result}

This study uses the monthly data of the Japan EPU index and the real ER ranging from June 1988 to April 2016; these two variables are available from the Federal Reserve Bank of St. Louis. The definition of the real ER considers the nominal ER that incorporates the inflation differentials among the countries; this is deemed to reflect the actual relation between two currencies. The sample period begins at the stage of the large surge in asset prices and the expansion of economic activity in 1988. Thereafter, a series of impactful economic recession events occurred, such as the collapse of the asset price bubble beginning in the early 1990s followed by a prolonged economic contraction; the Asian financial crisis in the late 1990s; and the global financial crisis that began the summer of 2007. Furthermore, the three-times QE programs and Abenomics all occurred in these periods. Both the EPU and the ER were transformed by using natural logarithms to correct for potential heteroscedasticity.

We then test the full-sample causal relationship between the two variables using the VAR model in Table 1. The bivariate VAR models are the ER and the EPU, which are constructed as in Equation (6). Per the bootstrap p-values, the ER does not Granger cause EPU, and vice versa, in the full-sample test. This finding contradicts the existing literature (Beckmann and Czudaj, 2017), which argues that a bidirectional causal link between the EPU and the ER exists. We consider whether structural changes lead to this conflict; thus, it is critical to reexamine the data and improve the methodology.

Table 1. Full-Sample Granger Causality Tests

\begin{tabular}{|l|c|c|c|c|}
\hline Tests & \multicolumn{2}{|l|}{$\mathrm{H}_{0}$ : ER does not Granger cause EPU } & \multicolumn{2}{l|}{$\mathrm{H}_{0}$ : EPU does not Granger cause ER } \\
\hline & Statistics & $p$-values & Statistics & $p$-values \\
\hline Bootstrap LR Test & 1.965 & 0.170 & $3.292^{*}$ & 0.060 \\
\hline
\end{tabular}


Zheng-Zheng Li, De-Ping Xiong, Lavinia Daniela Mihit, Cristina Stanciu - Mandruleanu, Florin Costea

Note: $*$ indicates significance at the $10 \%$ level.

When the structural break is emerging, the parameters are no longer constant (Su et al., 2016). Consequently, this paper firstly tests for parameter stability and examines the structural changes. Table 2 shows the corresponding results of above tests. For the Sup- $F$ test, the null hypothesis is that parameters have no one-time sharp shift. The results suggest that a one-time sharp shift exists in the ER and the VAR system at the 10\% level and exists in the EPU at the 5\% level. The null hypothesis for Mean- $F$ and Exp- $F$ test is that the parameters follow a Martingale process. The hypothesis is also rejected in light of $p$-values in the second and third row, which indicates equations from ER, EPU and VAR system might evolve gradually. The parameters submitting to a random walk process constitutes the null hypothesis for $L c$ test and the assumption is also rejected. That means parameter in the overall VAR system is non-constant. Consequently, these provide enough evidence to reject the null hypothesis and prove there exist structural breaks. The FM-OLS estimator is used to estimate the cointegration between the two variables; the Sup- $F$, Mean- $F$, and Exp- $F$ tests as well as the $L c$ test are conducted to check the parameter stability of the long-run relationship. The results are summarized in Table 3.

Table 2. Parameter Stability Tests

\begin{tabular}{|l|l|l|l|l|l|l|}
\hline & \multicolumn{2}{|c|}{ ER Equation } & \multicolumn{2}{c|}{ EPU Equation } & \multicolumn{2}{c|}{ VAR System } \\
\hline & Statistics & $p$-value & Statistics & $p$-value & Statistics & $p$-value \\
\hline Sup-F & $9.495^{*}$ & 0.063 & $10.356^{* *}$ & 0.048 & $16.727^{*}$ & 0.057 \\
\hline $\begin{array}{l}\text { Mean- } \\
F\end{array}$ & $5.406^{* *}$ & 0.046 & $4.049^{*}$ & 0.061 & $8.723^{*}$ & 0.064 \\
\hline Exp-F & $3.046^{*}$ & 0.051 & $2.850^{*}$ & 0.069 & $5.430^{*}$ & 0.079 \\
\hline$L_{c}$ & & & & & $1.373^{* *}$ & 0.041 \\
\hline
\end{tabular}

Table 3. Parameter Stability Tests in long-run relationship FM-OLS

\begin{tabular}{|l|c|c|c|c|}
\hline Tests & Sup- $F$ & Mean- $F$ & Exp- $F$ & $L_{c}$ \\
\hline ER=a+b*EPU & $205.231 * * *$ & 114.657 & 98.139 & $14.710^{* * *}$ \\
\hline$p$-values & 0.000 & 1.000 & 1.000 & 0.005 \\
\hline
\end{tabular}

Note: $* * *$ indicates significance at the $1 \%$ level. 
How Does Economic Policy Uncertainty Effect Signaling Exchange Rate In Japan?

In the sub-sample rolling-window causality test, the null hypothesis of the tests is that the EPU does not Granger cause ER and vice versa. The bootstrap $p$-values of $L R$-statistics can be estimated by using the rolling sub-sample data with the $24-$ month $^{1}$ observations. This window size excludes the observations required for lags and, hence, is the actual number of observations in the VAR. Figure 1and Figure 3 show the rolling bootstrap of the $p$-values of $L R$-statistics using the ER and the EPU as dependent variables, respectively. Figure 2and 4 show the bootstrap estimates of sum of the rolling coefficient measuring the magnitude of the causality relationship.

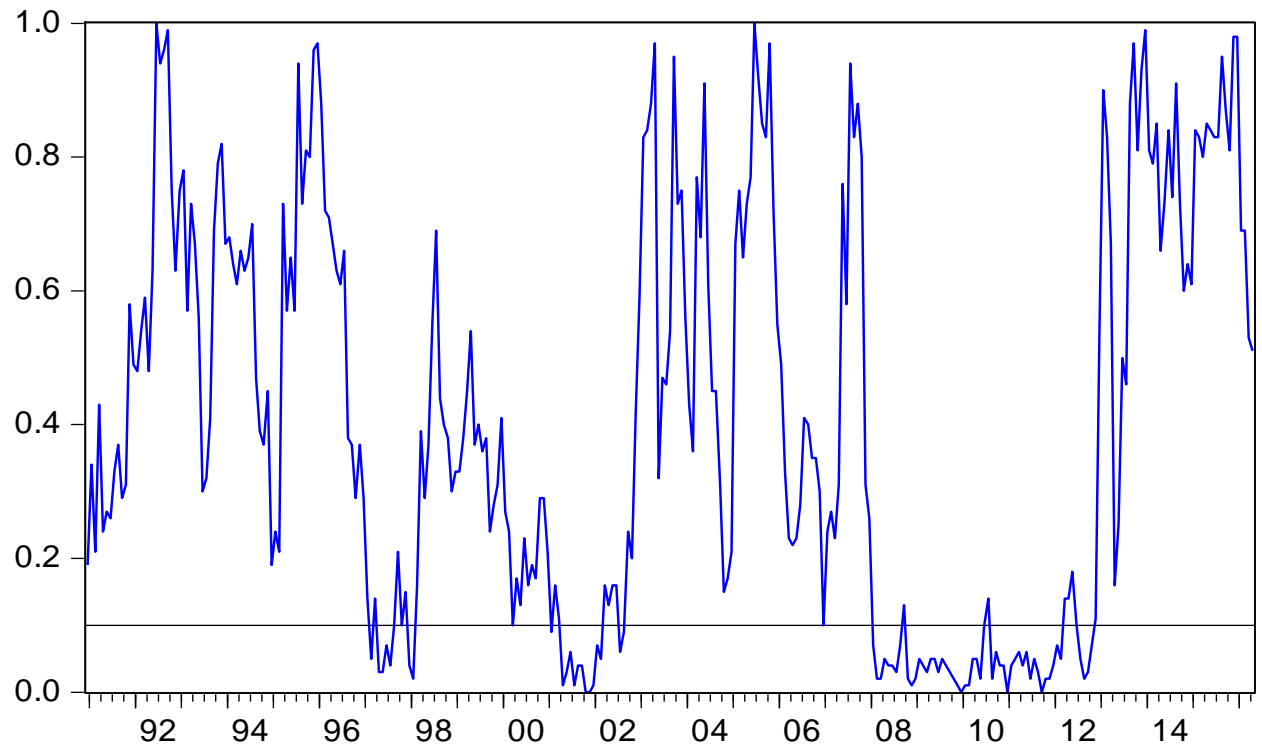

Figure 1. Bootstrap $p$-values of rolling test statistic testing the null that EPU does not Granger cause ER

1. No consistent criterion is provided to select the window size in the rolling-window estimation (Balcilar et al., 2010). Nevertheless, we wonder whether the results are sensitive to the choice of the window interval. Therefore, we conduct several iterations by using different month-window sizes (e.g. 24,30 and 36 months). The findings present very little difference. We want to find the structural changes caused by Japan's policy regime changes within the shortest time. We therefore select a 24-month window size. 
Zheng-Zheng Li, De-Ping Xiong, Lavinia Daniela Mihit, Cristina Stanciu - Mandruleanu, Florin Costea

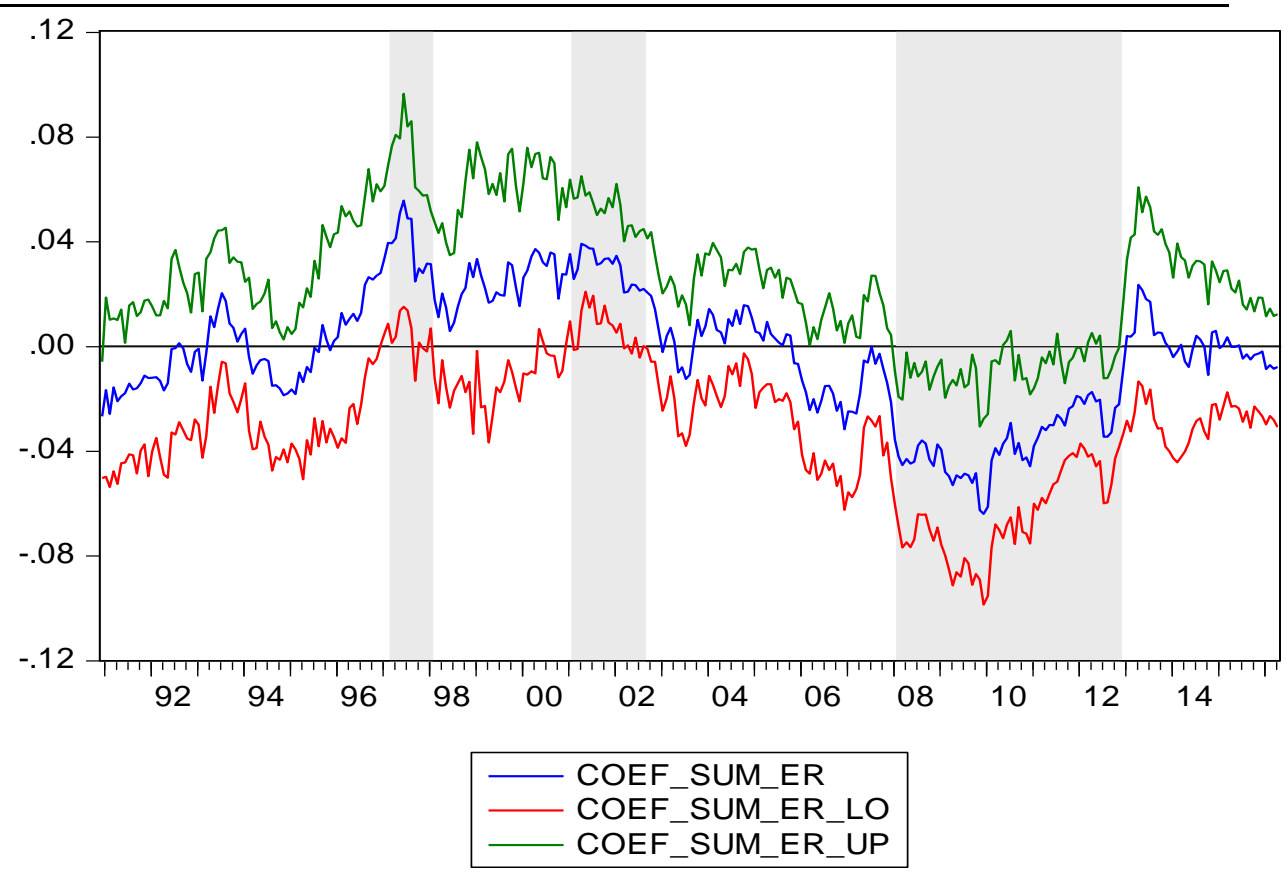

Figure 2. Bootstrap estimates of the sum of the rolling-window coefficients for the impact of EPU on ER.

We clearly find that the null hypothesis is rejected in 1997:02-1998:01; 2001:01-2002:08 and 2008:01-2012:11, which indicates that the EPU has different effects on the ER in different periods in Japan. Figure 2 indicates that, in 1997:02-1998:01; 2001:01-2002:08, the EPU exerts a positive effect on the ER, while in the sample from 2008:01 to 2012:11, the relationship of the two series is negative. The Asian emerging-market financial crisis furiously erupted in 1997, contributing to the financial instability. This crisis begins with interbank market turmoil triggered by the default of Sanyo Securities in 1997 andresulted in the collapses of large banks and security companies such asHokkaido Takushoku Bank and Yamaichi Securities (Hirakata et al., 2016). Hoshi and Kashyap (2010) acknowledge that Japanese banks suffered from non-performing loan problems and record loan losses of approximately 13 trillion Yen in this crisis, and their balance sheets were severely impaired. Substantial uncertainty components promoted the EPU index, making the economy more complicated. The ER elevated with the increase of the EPU; that is, the Yen tended to depreciate. In 2000, the Yen depreciated because of the rise of the EPU. The EPU rose because, on the one hand, the Japanese monetary authorities have frequently resorted to intervene on behalf 
How Does Economic Policy Uncertainty Effect Signaling Exchange Rate In Japan?

of their currency to help the domestic economy recover from a prolonged recession by selling the Yen in foreign exchange markets and purchasing Dollars (Fatum and Hutchison, 2006). On the other hand, the speculators took the opportunity to speculate, which aggravated the expectation of the Yen's depreciation. In addition, Bank of Japan (BOJ) expressed that adjustments in the economic activity were becoming more severe considering the employment and income conditions, which made the public less confident in Japan's economy. One financial market shock that likely originated from the subprime mortgage crisis in the U.S. spread greatly to the world in 2008. The impact was propagated to the Japanese economy through international trade. Japan's trade dependence has increased since the early 2000s, and it is particularly vulnerable to a negative demand shock that originates from outside. The economy was adversely impacted by the 2008 recession. The registered annual GDP growth rate in Japan in 2009 was at the $-5.5 \%$ level, due to the severe decline in real exports of $26.2 \%$ (Hirakata et al., 2016). The Yen began to strengthen sharply in the fall of 2008, behaving as a relative safe haven in global financial market crisis. Furthermore, portfolio rebalancing through offshore derivative transactions occurred contemporaneously to Yen risk-off appreciations.

Figure 3 presents the null hypothesis should be rejected in certain periods (1994:04-1994:07; 1998:07- 2000:05; 2003:03-2003:08; 2004:10-2005:12; 2013:03-2014:09). Figure 4 reports the rolling estimates of the magnitude of the effect that the ER has on EPU. Specifically, in the sample of 1994:04-1994:07, 2003:03-2003:08 and 2013:03-2014:09, the ER has a negative effect on the EPU, while the ER has a positive effect on the EPU in 1998:07- 2000:05 and 2004:10-2005:12. With Japanese long-term real interest rates exceeding those of the USA and a continuous rise in short-term rates, the Yen began to appreciate sharply. Japan notched a record-breaking trade surplus with the USA, adding to the tense atmosphere regarding trade. To release the intensified trade imbalances, both sides conducted a series of trade negotiations; however, in the automobile industry, a large proportion of trade surplus remained unresolved. Thus, foreign exchange investors continued selling Dollars due to their negative expectation. Summed up all the components contribute to the rise of EPU. The Yen's next real appreciation cycle begin in July of 1998. During this period, Japan's real long-term interest rate rises relative to that in the USA. The overnight interest rate is at a level below $0.5 \%$ and would effectively decrease to zero within a year; only in the presence of deflation expectations would Yen appreciation continue. Japan's economy substantially improved between 1998:07 and 2000:05 due to certain factors that 
Zheng-Zheng Li, De-Ping Xiong, Lavinia Daniela Mihit, Cristina Stanciu - Mandruleanu, Florin Costea

support macroeconomic policies, including the reduction in problems over the financial system, the continued recovery of the world economy and the accelerated technological innovation in the broad information and communications domain. The Japanese economy is showing a clear sign of gradually recovery; this gradual upturn, which is mainly led by business fixed investments, is likely to continue in the future (Ito, 2006). Japan's Ministry of Finance (MOF) implemented interventions to sell 35256.4 billion Yen for Dollars in the foreign exchange market in 2003. The Nikkei stock price index decreased below 8000, merely one-fifth of its peak 13 years prior. The government became restrictive regarding the treatment of balance sheet accounting standards of major banks (Lobont et al., 2018). Certain banks required rescue by the government (Ito, 2006). The systemic stability of the financial markets was regarded as threatened, which explained why the EPU rose slowly. The MOF and BOJ sold a total of 35 trillion Yen and purchased approximately 317 billion Dollar in the first quarter of 2004 (Ito, 2006). The Fed had begun to tighten U.S. monetary conditions in mid-2004 in response to the mounting inflation pressure. Thus, the Yen depreciation accelerated, resulting in the EPU's increase. Shinzo Abe became prime minister and implemented a series of radical actions to end economic stagnation. Japan attempted to depreciate the Yen to foster exports and decrease imports; BOJ implemented policies to rapidly weaken the Yen. Abe has declared war on deflation, using the heavy armament of fiscal stimulus and monetary easing. Japan's fiscal outlook has improved sharply. In addition, exporters are cheering because the value of the Yen has depreciated considerably; this means that the EPU tends to decrease. 
How Does Economic Policy Uncertainty Effect Signaling Exchange Rate In Japan?

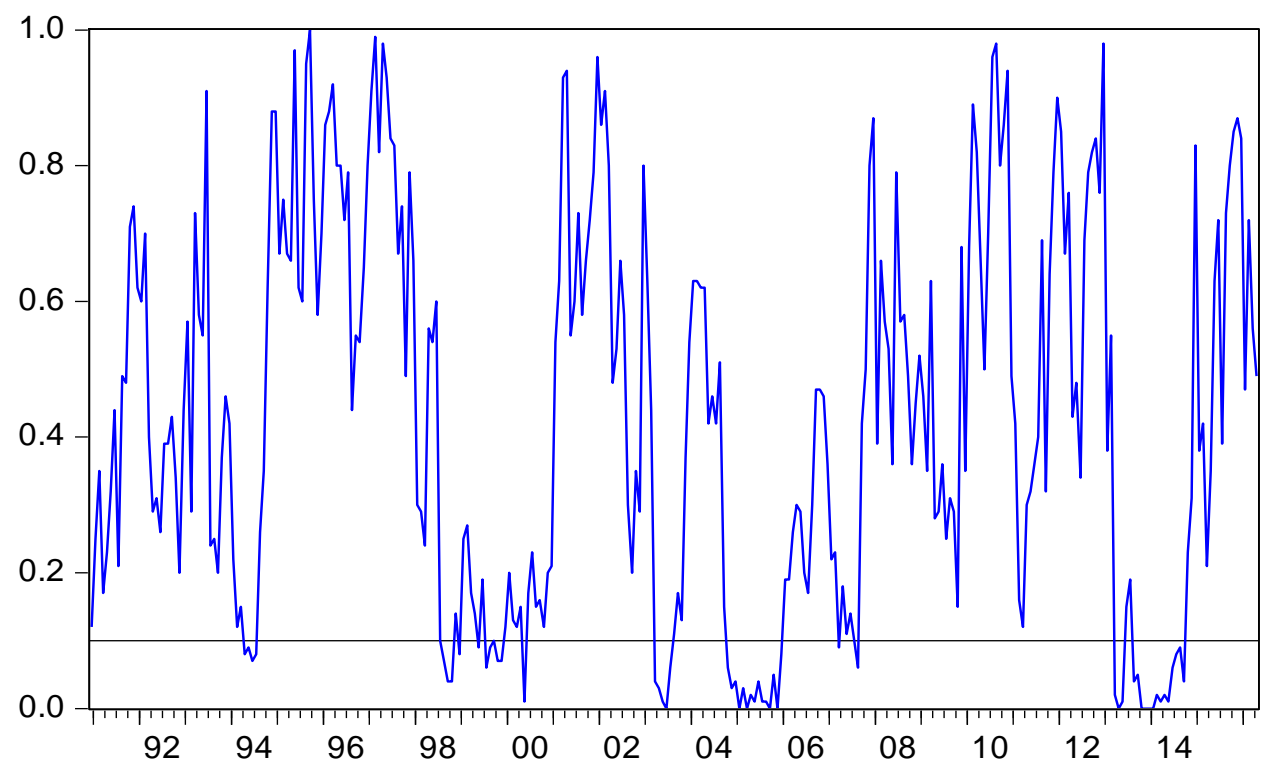

Figure 3. Bootstrap $p$-values of rolling test statistic testing the null that ER

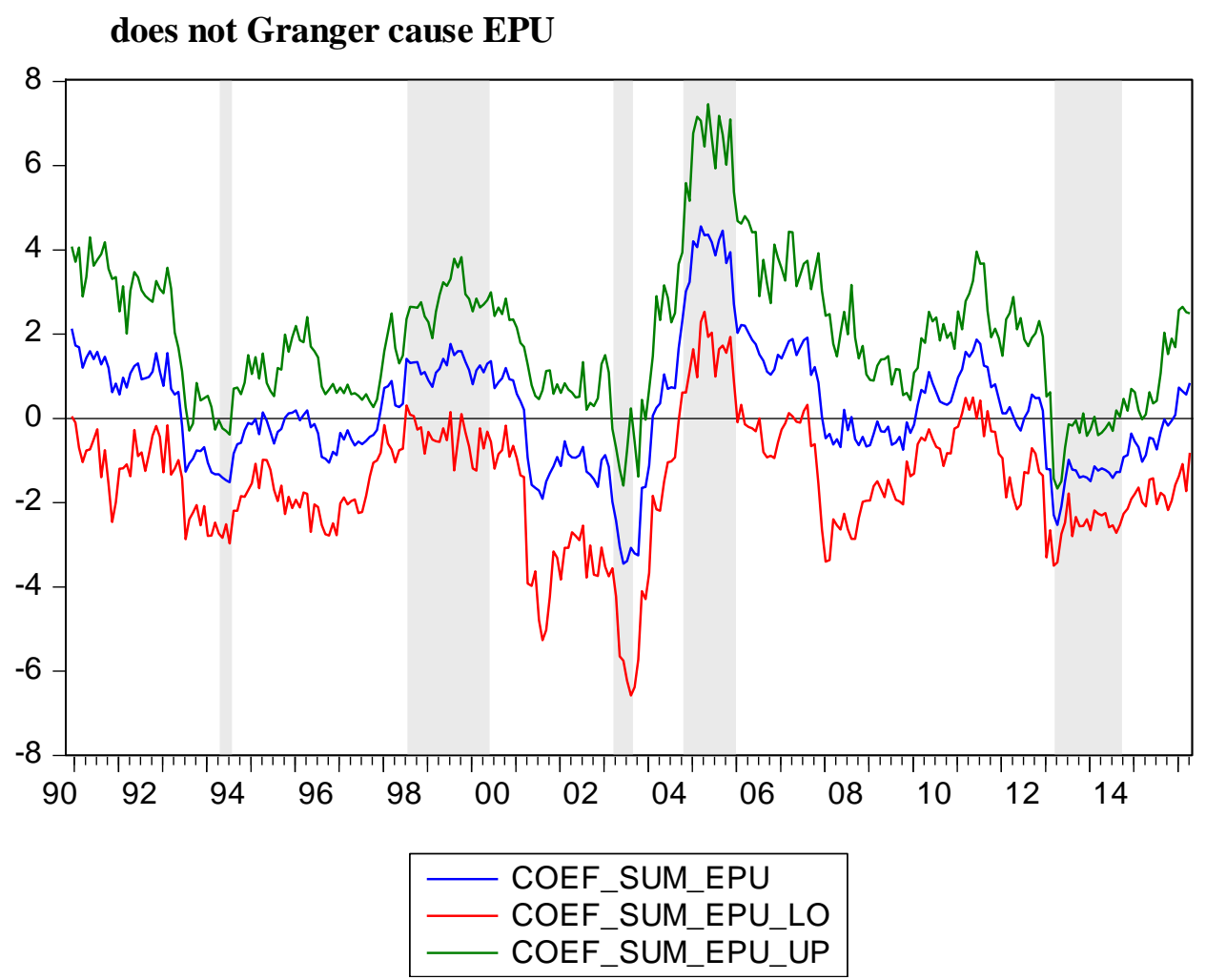

Figure 4. Bootstrap estimates of the sum of the rolling-window coefficients for the impact of ER on EPU. 
Zheng-Zheng Li, De-Ping Xiong, Lavinia Daniela Mihit, Cristina Stanciu - Mandruleanu, Florin Costea

Overall, the relationship between the EPU and the ER in Japan has not always been consistent with the theory of the Expected Value Model (Engel and West, 2005); this can be explained by the Yen's hedging function. Furthermore, it is not accurate to state that, with an increase in the EPU, asset price returns are decreasing, which is what much of the existing literature has presented. On the other hand, the ER can impact on the EPU when Yen is at the appreciation cycles. Based on the reported findings, the conclusion is that the correlation between the ER and the EPU is time-varying. In particular, we find that the correlations between the EPU and the Japanese Yen are consistently positive in 2008-2012. This finding suggests that the rise of the EPU caused the appreciation of the Yen; this verifies the established role of the Japanese Yen as a safe-haven currency (Ranaldo and Söderlind, 2010). In contrast to the experience of the Swiss Franc, the Yen risk-off appreciations appear unrelated to capital inflows and do not appear supported by the expectations regarding the relative stance of monetary policies. In addition, the EPU is more sensitive to the ER than vice versa, as illustrated by the high frequency that the EPU varies with the ER. This finding verifies the opinion of Demir (2014) that the ER is an important part of the transmission mechanism in the determination of economic policy because movements in the ER have a significant effect on the macro economy.

\section{Conclusion}

By employing the bootstrap rolling-window causality test, this paper explores the relationship between the ER and the EPU. Considering the structural changes, we find time-varying links in the sub-sample of these two series. The rolling window provides a more accurate perspective in investigating the causality between these two variables. These findings are basically consistent with the expected value theory proposed by Engel and West (2005), which expects certain special periods. The ER is changing with the EPU in the same direction, given the fixed fundamental components. When the Yen ER increases, the EPU increases accordingly and vice versa. However, the Yen shows a negative linkage during the financial crisis in 2008 and the Great East Japan Earthquake in 2011 when the EPU is rising. We can infer that the Japanese Yen is a safe-haven currency (Ranaldo and Söderlind, 2010) because of its risk-off characteristics during crisis periods. Thus, we can infer that the ER is an important indicator variable in the EPU and in the financial market. This paper has the following implications: Japanese authorities could implement the interventions for the ER to influence the public's expectation 
How Does Economic Policy Uncertainty Effect Signaling Exchange Rate In Japan?

to enable the EPU to smoothly stabilize the economy. The Yen is a valuable asset for hedging against the depreciation risk in global economic recession periods for market participants.

\section{REFERENCES}

[1] Andrews, D. W. K., Ploberger, W. (1994), Optimal Tests when a Nuisance Parameter is Present only under the Alternative. Econometrica 62(6), 1383-1414;

[2] Badîrcea, R., Manta, A., Pîrvu, R., Florea, N. (2016), Banking Integration in European Context. Amfiteatru Economic Journal, 18(42), 317-334;

[3] Baker, S.R., Bloom, N., Davis. S.J. (2016), Measuring Economic Policy Uncertainty. Quarterly Journal of Economics 131, 1593-1636;

[4] Balcilar, M., Ozdemir, Z. A., Arslanturk, Y. (2010), Economic Growth and Energy Consumption Causal Nexus Viewed through a Bootstrap Rolling Window. Energy Economics 32(6), 1398-1410;

[5] Balcilar, M., Gupta, M., Kyei, C., Mark. E. (2016), Does Economic Policy Uncertainty Predict Exchange Rate Returns and Volatility? Evidence from a Nonparametric Causality-in-Quantiles Test. Open Economies Review 27, 229-250;

[6] Beckmann, J., Czudaj, R. (2017), Exchange Rate Expectations and Economic Policy Uncertainty. European Journal of Political Economy 47, 148-162;

[7] Bloom, N., Bond, S., Reenen. J. V. (2007), Uncertainty and Investment Dynamics. Review of Economic Studies 74, 391-415.;

[8] Brogaard, J., Detzel. A. (2015), The Asset Pricing Implications of Government Economic Policy Uncertainty. Management Science 61, 3-18;

[9] Engel, C., West, K. D. (2005), Exchange Rates and Fundamentals. Journal of Political Economy 113, 485-517;

[10] Fatum, R., Hutchison, M. (2006), Effectiveness of Official Daily Foreign Exchange Market Intervention Operation in Japan. Journal of International Money and Finance 25(2), 199-219;

[11] Frankel, J. A., Meese. R. (1987), Are Exchange Rates Excessively Variable? NBER Macroeconomics Annual 2, 117-53;

[12] Ganea, M. (2015), Determinant Factors of the Economic Value Added in the Case of Romanian Companies Listed on the Bucharest Stock Exchange. Audit Financiar, 13 (121), 100-107; 
Zheng-Zheng Li, De-Ping Xiong, Lavinia Daniela Mihit,

Cristina Stanciu - Mandruleanu, Florin Costea

[13] Hansen, B. E. (1992), Tests for Parameter Instability in Regressions with I(1) Processes. Journal of Business and Economic Statistics 10(3), 321-336;

[14] Hirakata, N., Sudo, N., Takei, I.,Ueda, K. (2016), Japan's Financial Crises and Lost Decades. Japan and the World Economy 40, 31-46;

[15] Hoshi, T., Kashyap, A.K. (2010), Will the U.S. Bank Recapitalization Succeed? Eight Lessons from Japan. Journal of Financial Economics 97, 398-417;

[16] Ito, T. (2006), Japanese Monetary Policy, 1998-2005 and beyond. Monetary policy in Asia, approaches and implementation. Bank for International Settlements 31, 105-132;

[17] Lobont, O. R., Moldovan, N. C., Bociu, A., Chis, C., Brindescu Olariu, D. (2018), A Factor Analysis of the Public Sector Performance. Significant Differences between Old and New EU Countries. Economic Computation \& Economic Cybernetics Studies \& Research, 52(2);

[18] Nyblom, J. (1989), Testing for the Constancy of Parameters over Time. Journal of the American Statistical Association 84 (405), 223-230;

[19] Pesaran, M.H., Timmermann, A. (2005), Small Sample Properties of Forecasts from Autoregressive Models under Structural Breaks. Journal of Econometrics 129(2), 183-217;

[20] Ranaldo, A., Söderlind, P. (2010), Safe Haven Currencies. Euro-Finance Reviews 14, 385-407;

[21] Shukur, G., Mantalos, P. (2000), A Simple Investigation of the Granger-Causality Test in Integrated-Cointegrated VAR Systems. Journal of Applied Statistics, 27 (8), 1021-1031;

[22] Sims, C. A., Stock, J. H., Watson, M. W. (1990), Inference in Linear Time Series with Some Unit Roots. Econometrica 58(1), 113-144;

[23] Sin, C. Y. (2015), The Economic Fundamentals and Economic Policy Uncertainty of Mainland China and their Impacts on Taiwan and Hong Kong. International Review of Economics \& Finance 40, 298-311;

[24] Su, C. W., Khan, K., Lobont, O. R. \& Sung, H. C. (2016), Is there any Relationship between Producer Price Index and Consumer Price Index in Slovakia? A Bootstrap Rolling Approach 1.EkonomickyCasopis, 64(7), 611;

[25] Ulrich, M. (2012), Economic Policy Uncertainty and Asset Price Volatility. Social Science Electronic Publishing 89(4), 301-303. 